REVISTA CHILENA DE LITERATURA

Abril 2009, Número 74, 241 - 250

\title{
EL ÓRGANO ENFERMO DE LA PATRIA. RETÓRICA NATURALISTA EN LOS TRASPLANTADOS DE ALBERTO BLEST GANA
}

\author{
Luigi Patruno \\ Universidad de Buenos Aires \\ patruno_luigi@libero.it
}

En respuesta a la emergente preocupación política sobre la identidad nacional en Latinoamérica, la literatura decimonónica se hizo proveedora de un caudal de lecturas posibles que alimentó los imaginarios comunitarios. La articulación entre práctica literaria y política del Estado asumió en determinados contextos una urgencia inmanente al proceso de modernización, tanto literaria como estatal ${ }^{1}$. Frente a la desarticulación entre espacio público y tarea civilizadora del intelectual orgánico, escisión inmanente a la autonomización de la literatura (Ramos, Desencuentros 9), las estrategias gubernamentales argentinas de cooptación de intelectuales registran cómo a veces los escritores legitimaron y hasta intervinieron activamente, desde la esfera en proceso de privatización del arte, para reforzar los discursos identitarios proporcionados por el estado liberal (Dalmaroni). Esta variable de escritura se oponía a otra cuyo gesto negativo pasó a definir la esencia de su modernidad. Sin embargo, aun cuando la relación entre oficio literario y función estatal operó bajo el signo de la negación, y la modernización literaria se configuró como rechazo de las leyes del pragmatismo burgués y de la lógica del mercado, la representación de lo nacional no dejó de operar en los discursos literarios.

Por su parte, Alberto Blest Gana pertenece todavía a la generación de escritores que se veían involucrados activamente en el proceso de formación nacional. Es conocido su discurso leído en 1861, al incorporarse a la Facultad de Humanidades de la Universidad de Chile, donde pudo jactarse prematuramente de que el país poseía ya una literatura propia ${ }^{2}$.

1 Se trata del caso particular de la Argentina de fin de siglo.

2 La rápida consolidación del Estado-nación es, según Julio Ramos, la razón por la cual el saber en Chile se privatizó muchos antes que en los otros países latinoamericanos: "Dada la relativa centralización y consolidación del Estado en Chile, el saber (no hablamos todavía 
En esa ocasión, la propuesta de una normalización genérica, centrada en el privilegio concedido a la novela costumbrista sobre las otras formas de escritura, coincidió con el reconocimiento de la tarea civilizadora implícita en la práctica literaria:

Mientras que la poesía conserva siempre para el vulgo la apariencia de los antiguos ídolos [...] la novela, por el contrario, tiene un especial encanto para toda clase de inteligencia, habla el lenguaje de todos, pinta cuadros que cada cual puede a su manera comprender y aplicar, y lleva la civilización hasta las clases menos cultas de la sociedad (Blest Gana, Literatura chilena 53, énfasis mío).

A través del estudio de las costumbres locales, la novela autoritaria que "lleva la civilización hasta las clases menos cultas" se proponía esencialmente como "nacional", haciendo del mejoramiento social el argumento programático para la literatura del futuro.

Si en Martín Rivas (1862) la pregunta había sido por el cuerpo de la nación chilena, en Los trasplantados (1904) el interrogante es desplazado hacia la identidad continental. La crítica ha insistido en una lectura autobiográfica de la última novela extensa de Blest Gana, buscando, ahí donde el novelista evita decirlo, los presuntos rasgos cifrados de la chilenidad (cfr. Silva Castro; Durán Luzio; Latcham). Sin embargo, en ningún momento es explicitado en el texto el país de origen de los Canalejas -la familia protagonista de Los trasplantados-, ni el de los otros integrantes de la comunidad hispanoamericana en París. Por esta razón, el perfil identitario propuesto para la comunidad indagada trasciende las localidades. En efecto, la novela explora las posibilidades de la entera comunidad hispanoamericana trasplantada en la capital europea. Del mismo modo, ella supera el contexto local y participa de retóricas y preocupaciones que circularon en las postrimerías del siglo XIX en toda América Latina.

Las teorías positivistas que postulaban la vinculación de los seres, y que entretejían encadenamientos entre materia orgánica e inorgánica, constituyeron una fuente paradigmática para la interpretación de hechos sociales. El saber científico, apreciado como el desencadenador del progreso, se acomodó al análisis de problemáticas nacionales. A partir de la vertiente médica del conocimiento, se organizó luego una lectura que aproximaba las sociedades a organismos y las crisis sociales a enfermedades (Terán). Eugenio María de Hostos explicaría elocuentemente esta concepción simultánea:

Las sociedades, como los individuos, están sujetas a enfermedad. Esto, por una parte, está dentro de la Ley del Progreso, y, por otra parte, es resultado de la Ley de los Medios. En virtud de la Ley del Progreso, todo cuanto es capaz de crecimiento, es susceptible de decrecimiento. De aquí, enfermedad. En virtud de la Ley de los Medios, toda fuerza debilita su acción, según el medio. De aquí, también, enfermedad (Hostos 176).

de literatura) ganaba cierta autonomía de la administración inmediata o de la proyección de la vida pública" (Desencuentros 38). 
Las hipótesis de Lamarck, que proponían la heredabilidad del carácter, concedieron al entorno y a las prácticas individuales un importante valor, hasta alimentar toda una tradición de políticas estatales que confió en la pedagogía como medio para "moldear y civilizar a los seres humanos" (Terán 96). Las enfermedades sociales se hacían proceder de la herencia, de fenómenos atávicos, pero también del desconcierto económico y de los desórdenes jurídicos (Hostos 176-177). En este horizonte, la corrupción biológica pasó por metonimia a describir decadencias morales, desvíos corporales que la lógica del estado burgués necesitaba disciplinar. La novela naturalista en su articulación con los programas de racionalización estatal se alimentó de este dispositivo ideológico. En ella, "la escritura y el arte particular de narrar son instrumentos prácticos para fabricar ficciones estatales que, mediante la postulación de dominios socio-biológicos, trazan las fronteras físicas y la organización interna de las nuevas comunidades imaginarias hispanoamericanas" (Nouzeilles 149).

Es así como la literatura puertorriqueña insiste, por ejemplo, en "leer la enfermedad como metáfora del colonialismo", al privilegiar justamente las novelas de Manuel Zeno Gandía en la incipiente constitución del canon (Gelpí 7); o como José Carlos Mariátegui patologizaría "la flaqueza, la anemia, la flacidez" de la literatura colonial peruana, fatalmente unida al "enfermo cordón umbilical” de la metrópoli (72). La articulación entre políticas higienistas y literatura en Argentina (Nouzeilles), las degeneraciones físicas y morales que circulan en las novelas de Orrego Luco como somatizaciones de disturbios políticos (Ara), apenas dan cuenta de la imbricación entre el discurso científico y prácticas literarias en Latinoamérica.

En la novela de Blest Gana, el narrador busca insistentemente los síntomas de la enfermedad social de los trasplantados. Esta configuración jerárquica entre observador y observado comparte con la práctica naturalista la situación narrativa del caso clínico. Sin presentar directamente médicos y pacientes, la narración se organiza según el esquema operacional de la diagnosis y el cuerpo analizado se convierte en "un texto pasible de una lectura semiológica" (Nouzeilles 60). La voz autoritaria del narrador reordena los signos diseminados de la patología devolviendo un diagnóstico coherente a las lógicas de la homologación biológico-moral. A partir de esta mirada agresiva arrojada sobre el cuerpo de la patria se organiza una serie de operaciones selectivas que, o rescatan los cuerpos por sanos o los desechan por enfermos. El recorrido que siguen estas intervenciones configura un mapa en donde salud y enfermedad se distribuyen según el modelo deseado o rechazado de la comunidad hispanoamericana imaginada.

La metáfora de la enfermedad opera insistentemente en el texto. El título mismo tematiza el cruce entre discurso literario y procedimientos médicos. El cuerpo de la patria sufre un trasplante. Pero, contrariamente a toda expectativa, a la traslación sigue una paulatina corrupción del órgano nacional. Esta complicación es explicitada a través de los peligrosos síntomas de la hibridez:

Poco á poco, la transformación moral que el contagio del ejemplo opera en las ideas, en los gustos, en las costumbres, así como la influencia lenta, pero segura, del clima sobre los órganos del cuerpo había hecho de los padres y de los hijos Canalejas un tipo híbrido de dos civilizaciones, del que tantas familias hispano-americanas 
trasplantadas á la Ciudad Luz, como la llaman sus escritores, presentan característicos ejemplos (I 39).

La patologización de la mezcla cultural, resultante del "contagio" moral causado por el entorno, es producida en el espacio infectivo europeo. Los lugares de la salud y de la enfermedad delinean una cartografía en la que se enfrentan la patria sana hispanoamericana y la Europa decadente.

Utopías raciales y determinismo convergen en una encrucijada hermenéutica en la que el medio ambiente apenas concurre a lo que la ley de la heredabilidad ya había predispuesto. Los jóvenes aristocráticos europeos llevan los estigmas físicos de la decadencia moral. La voz narrante patologiza los deseos de una generación de depravados, sus locuras alcohólicas y las desenfrenadas carreras sexuales. Estos desvíos morales dejan restos visibles sobre los cuerpos, pero el único capaz de descifrar la trama de esas marcas es el narrador autorizado por el saber letrado. El aspecto anémico del marqués Arsenio Varielle-Landry es efecto de las insidias del juego y de los solaces amorosos; su sonrisa lánguida expresa el prematuro desgaste que provocan las disipaciones capitalinas. El semblante del vizconde Vieux-Pont, luego, excede el simple color amarillento de la piel y exhibe los rasgos de una anomalía atávica: "un mozalbete de baja estatura [...] de veinte á veintiún años, ojerudo y raquítico, en el que la trasnochada aumentaba la cavidad de las mejillas y la prominencia aguda de los juanetes de la cara" (I 76). El barón Boisrocheus es el ejemplo espantoso del degenerado: "pertenecía, como sus dos compañeros, á ese tipo de degenerados precoces en los que los desarreglos tempranos de una existencia sin freno interrumpen el desarrollo natural del cuerpo" (I 76).

La lenta decadencia moral desencadenada por el medio europeo no deja de manifestarse sobre la piel. De los órganos nacionales trasplantados, Juan Gregorio, hijo de don Graciano Canalejas, es la parte que sufre la más drástica metamorfosis y la completa parálisis del crecimiento corporal. Pálido, imberbe, cuyo cuello oscurecido deja el paso a la visión aterradora de mejillas caídas bajo ojos cansados, Juan Gregorio somatiza la disipación moral y acompaña los defectos corporales con las carcajadas roncas y las sonrisas amarillentas. Una tos crónica "que nunca acaba de curarse" (I 169) incita una decadencia precoz acentuada por las trasnochadas alcohólicas y los ritmos de la vida alegre parisina. A diferencia de su tío Jenaro Gordanera, quién continuamente ingiere pastillas "para combatir una bronquitis crónica que, según él, no lo dejaba" (I 43) -exceso hipocondríaco de su oposición al clima europeo-, Juan Gregorio sufre la "enfermedad del chic" ( $I$ 68) que lo condena al exilio de la comunidad imaginada.

Al otro lado del mapa, la imagen de la patria ideal es organizada alrededor de la moral del trabajo y de la lógica pragmática depositada en la figura de Patricio Fuentealba. Frente a la degeneración de la juventud europea, lo positivo de su promesa está garantizado en la narración por el perfil del hombre sano: "él no era de la raza de los neurasténicos, que buscan el alivio a los dolores morales en la disolución ó en la bebida. Su sistema nervioso y la integridad de su mente estaban intactos" (II 276). Sus proyectos corresponden a la única regeneración posible para los trasplantados: el regreso a la patria y la inversión de la fuerza-trabajo en las tierras hispanoamericanas. El éxito de estas aspiraciones sería posible si solo se concretara su unión con Mercedes, la única entre los hijos de don 
Graciano que desea dejar París y volver al suelo natal. Ella difiere de sus hermanos no solo en las intenciones, sino también en lo que concierne a lo biológico:

También las separaba la naturaleza, moral y físicamente. Mientras Dolores y Milagros, como lozanas y apetitosas frutas medio tostadas por el sol meridional, recataban apenas el fuego de sus negros ojos con las espesas y crespas pestañas de sus párpados sombríos, en Mercedes lo blanco del cutis, los cabellos rubios, el suave mirar de los ojos azules, la elevada y fina estatura, marcaban una interrupción de raza, como si reprodujera en ella el tipo de algún antepasado desconocido" (I 30).

Pero, Alberto Blest Gana decide no repetir la unión utópica planteada en Martín Rivas. Según la lectura del "romance fundacional" propuesta por Doris Sommer, las bodas de Martín celebraban el despliegue de un preciso programa ideológico en el que el desenlace de la intriga amorosa coincidía con la resolución de conflictos políticos. $\mathrm{Su}$ unión con Leonor alegorizaba la alianza fundacional del estado moderno chileno entre burgueses liberales, mineros disidentes y aristocracia, alianza posibilitada gracias a la condescendencia de Edelmira cuya función simbólica remitía al sacrificio de las clases populares (Sommer 213). En Los trasplantados, la subversión de la lógica conciliadora, confirmada por el rechazo que los Canalejas oponen al casamiento de Mercedes con Patricio y por el consiguiente fracaso de la unión que deciden entre la joven y el príncipe de Roespingsbrück, conlleva una versión alternativa de la utopía comunitaria. Como las otras ficciones del naturalismo estatal latinoamericano, ella consiste principalmente "en una re-escritura escéptica de las articulaciones narrativas conciliadoras del romance fundacional" (Nouizeilles 15), orientada, a la manera de las novelas naturalistas chilenas, "hacia una recia e incisiva caracterización de los males sociales de la nación" (Cánepa 32).

Con el suicidio de Mercedes, el relato se ajusta a la modulación de la ficción étnica continental $^{3}$. El fracaso de su matrimonio con el príncipe europeo deviene asunto de incompatibilidad biológica. El texto insiste particularmente en la utopía racial del matrimonio tradicional entre criollos. Como asegura Jenaro Gordanera, "cada cual debe casarse con los de su raza, sobre todo entre los hispano-americanos; todos deben volverse a su país, allá donde los estiman y donde pueden gastar su dinero con provecho de la patria común" (I 166). Es por esto que la novela construye una versión paralela a otros discursos raciales de fin de siglo. La disyunción con esos otros relatos radica en el espacio que presencia la imposibilidad de la mezcla y en la clase social patologizada. Mientras que en los informes policiales o en la mayoría de los ensayos antropológicos latinoamericanos la raza enfermiza es generalmente la de inmigrantes europeos o de subalternos criollos, en Los trasplantados el origen de la degeneración es depositado en la corrupción moral de las aristocracias europeas.

3 “la narración étnica de la nación se organizó de acuerdo con las convenciones de los relatos de parentesco y la lógica de los lazos de sangre" (Nouzeilles 19). 
El sacrificio de Mercedes anticipa la derrota en que irremediablemente se incurriría si se confiara en el proyecto nacional de los expatriados, los opulentos hispanoamericanos que gastan sus riquezas en las tierras europeas. El narrador insiste en que el órgano trasplantado decae inexorablemente y que solo es posible su recuperación una vez reinsertado en las tierras patrias. El suicidio, como desenlace fatal de la debilidad neurasténica producida por el entorno, demuestra cómo hasta el último símbolo de la identidad hispanoamericana carece de las virtudes necesarias a la constitución de una nación sana. La resolución final de Mercedes coincide con la pérdida de la ciudadanía y la expulsión de los trasplantados del cuerpo de la patria.

Entre las posesiones en crisis, la lengua nacional contaminada por los inmigrantes que llegaban a América constituyó un importante núcleo de reflexión para las elites liberales y su defensa, un desafío para las instituciones estatales. Los alcances del proceso que llevó en América Latina a la conjunción de formación estatal y racionalización lingüística, no pueden ser percibidos en su plenitud sin tener en cuenta el proyecto de Andrés Bello. La práctica literaria converge en la producción industrial y la retórica del "saber decir", de la gramática y elocuencia que someten la lengua hablada al control de la escritura, coincide con el proyecto de asimilación de las materias primas al régimen de la productividad del mercado. A través del saber decir, las letras cumplen con la fundamental tarea de formación de ciudadanos disciplinados, alejando, a la vez, el temor de una fragmentación lingüística de América Latina que acarrearía la derrota legisladora (Ramos, Desencuentros).

Años más tarde, en las ficciones abolicionistas cubanas, la hermenéutica del novelista permitiría interpretar la voz del subalterno. Las esclavas mulatas protagonistas de esas ficciones no hablan por sí. Afectadas por una especie de atavismo que les impide pronunciar su historia, deben renunciar a la elocuencia. No obstante, es justamente la inserción de este silencio en los textos lo que posibilita la exploración del enigma constitutivo de la nación. Es un ejemplo de cómo las leyes del habla siguen las leyes de la moralidad. En efecto, es notable la insistencia alrededor de un tópico: si por un lado, las mulatas ostentan el mutismo, por el otro, sus bocas parecen estar hechas solo para besar (Ramos, Faceless).

Esta igualación de lengua y moralidad tuvo acaso su mayor evidencia en la Argentina de fin de siglo. Varios de sus letrados contribuyeron a la condensación de una formación discursiva que hacía de la 'crisis del alma nacional' el resultado de una peligrosa contaminación lingüística, corrupción del idioma patrio hablado por los miles de inmigrantes llegados a las regiones australes. Frente a la aterradora posibilidad de la desintegración del español, la antropología criminal ofreció las razones para la patologización del habla ajena. El argot develaba psicologías degeneradas. Según el Lombroso de L'uomo delincuente, ampliamente difundido entre detectives, científicos y letrados argentinos, la homologación de aspectos lingüísticos y aspectos morales ilustraba claramente los matices criminales del alma: los delincuentes, y por ende los extranjeros, "hablan de manera salvaje, porque son salvajes" (Cit. en Ramos, Faceless 36).

Alberto Blest Gana desplaza la escena de la corrupción lingüística a Europa. Junto a la degeneración física y moral de los Canalejas, comienza la contaminación del idioma patrio caracterizada por la promiscuidad franco-española del habla. El espacio de la 
mezcla ya no es la América de la heterogeneidad lingüística, sino el París elegante al cual los trasplantados habían llegado para educar a sus hijos. Paradójicamente, la ciudad pedagógica se convierte en una zona de torpeza, un espacio en donde los Canalejas ni aprenden bien el francés, ni conservan intacto el castellano. En la caracterización de los personajes, el novelista ha concentrado las singulares combinaciones lingüísticas con las dudosas conductas morales de la familia hispanoamericana, dando lugar a una continuidad entre su indecente apetencia aristocrática y el carácter híbrido de su lengua. Entre el español y el francés, se organiza un espectro de la jerigonza que corresponde más o menos al grado de integración de los familiares al mundo malicioso europeo. A medida que avanzan las generaciones, el castellano se corromperá cada vez más. Entre doña Regis y sus pequeños nietos Nicolasito y Benjamina se introduce una serie de acentos que a partir del español lugareño hablado por la señora $\left(\begin{array}{l}I \\ 104\end{array}\right)$ degradará a través de la inclusión de palabras francesas proferidas por los niños con verbosidad meridional ( $I$ 236). La abuela, defensora de las costumbres patrias, nunca aprenderá francés y se negará a anudar cualquier tipo de relación con el ambiente capitalino; los niños, en cambio, se crían directamente en Europa y casi siempre hablan francés, "única lengua que sus padres, para que no pareciesen rastaquouères, les habían permitido aprender" (I 160). Entre estos dos extremos, los otros Canalejas concurren a la pluralidad de matices que asume la cuestión lingüística en Los trasplantados.

En la promiscuidad expresiva de Juan Gregorio radica el germen de la degradación. $\mathrm{Su}$ lengua entorpecida es reflejo de la decadencia moral y del rápido desgaste físico al cual se ha sometido desde su llegada a Europa; sus ocurrencias franco-españolas dan origen a roces con Jenaro Gordanera, quien le corrige los desórdenes idiomáticos; a pesar de esto, mezcla indistintamente modismos juveniles de la bohemia parisiense con locuciones tradicionales españolas. En particular, la condición inmoral de esta confusión es acentuada por el narrador luego de las trasnochadas alcohólicas del joven: "Mucho más acostumbrado al francés que al español, nunca hablaba en la lengua de sus padres cuando se encontraba en el estado de semi-embriaguez que le era frecuente en la noche" (II 508); "hablaba el muchacho, con su balbuciente pronunciación de bebedor achispado, á la que el acento francés daba en muchas palabras un sonido absolutamente grotesco para oídos hispano-americanos" (I 326). Las locuras alcohólicas de Juan Gregorio rehúsan el español; lengua y medio ambiente forman un todo corrupto y a las bajezas morales del bebedor se suma su "acento de erres guturales" (I 100).

El joven conforma con los otros muchachos de la colonia hispanoamericana el grupo que maneja preferiblemente el francés, en contraposición a la gente mayor que domina más bien el castellano (I 93). Junto con él, las hermanas Dolorcitos y Milagros exaltan el idioma europeo en desagravio de la lengua de los padres, código que corresponde según ellas al rasgo distintivo de los vulgares rastacueros. El uso exclusivo del francés por parte de las hermanas es una de las marcas que revelan su deseo de formar parte del mundo elegante de París. Entre este espacio y las tradiciones culturales patrias que los padres don Graciano y doña Quiteria aceptan abandonar, se proyecta el puente de la traducción necesaria. Y más que Canalejas, es doña Quiteria quien necesita de la constante ayuda de las hijas para poder acceder al mundo europeo. Al otro lado de la banda lingüística, en posición especular a la de Juan Gregorio, ella representa la resistencia natural que 
oponen las raíces hispanoamericanas a penetrar en las tierras del viejo continente. No entiende francés y lo único que puede hacer cuando se ve obligada a manejarse con el código europeo es decir "algunas palabras disparatadas en español afrancesado" (II 88). Al mismo tiempo, la extrema irracionalidad de su lengua le adjudica el más terrible de los pecados morales: ella se ha criado por allá y a sus deseos no se conceden las justificaciones que, en cambio, se acuerdan a los hijos criados en el ambiente contaminado de París. La necesidad interpretativa a la cual se ve obligada doña Quiteria remite a la distancia infranqueable entre los dos mundos, el de ultramar y el europeo.

En esta misma imposibilidad, aunque con efectos distintos, se posiciona el carácter lingüístico de don Graciano. A diferencia de su mujer, Canalejas puede hablar francés, con muchas dificultades, pero con el dominio suficiente para orientarse en el mundo de los negocios europeos. Casi siempre su lengua es fruto de una mezcla irritante; su español es proferido "con ridículo acento francés" (I 79) o "con detestable pronunciación francesa" (II 89). Hay una circunstancia que permite desentrañar las implicaciones ideológicas de esta promiscuidad lingüística. Se trata del último de los encuentros tenidos con la condesa Mortignan, embajadora de las solicitudes económicas del príncipe de Rœspingsbrück, futuro esposo de Mercedes. La enviada había pedido un ulterior aumento de la ya muy exorbitante dote. Después de negarse rotundamente, don Graciano se deja vencer por una última franca exclamación en español: “¡Vaya, estamos frescos!” (II 253). Al abandono de las palabras es agregada la espontaneidad de su gesticulación, comentada por el narrador en este modo: "decía lo último en español, de más y más estupefacto; y, por mejor expresar su sorpresa, se había puesto de pie, haciendo ademanes descompasados, algo como interjecciones accionadas, que no acertaba á expresar con voces conocidas de otras lengua que la suya" (II 253). Más adelante es explicitado el conflicto íntimo de Canalejas: "Don Graciano pugnaba con la dificultad de tener que expresarse en un idioma extraño, y con la no menos ardua de hallar frases que, evitando la ruptura, no lo comprometieran definitivamente" (II 255). La brecha existente entre los dos mundos es una vez más tematizada a través del habla trabajosa del hispanoamericano. La tensión entre lo que se reconoce como irremediablemente ajeno y el deseo a la integración con ese mundo otro, desemboca en la tragedia de un pacto absurdo y en una entrega a las leyes atroces de la diplomacia europea que llevará a los Canalejas hacia la desgracia.

A la vez, esta retórica de la exclusión lingüística desplegada a lo largo de la novela, manifiesta las analogías que el texto de Blest Gana comparte con los otros discursos relacionados con las definiciones nacionales. Como recuerda Adriana Rodríguez Pérsico, en la búsqueda de la identidad nacional, "de entre todas las posesiones, la lengua es quizás el tesoro más preciado. La institución literaria ensancha las fronteras cuando rescata a una lengua y a una literatura y les otorga el galardón supremo al nombrarlas nacionales" (24). La ridiculización de la extravagancia idiomática de doña Quiteria, la dramatización de las mediaciones lingüísticas de Canalejas, la patologización del habla de Juan Gregorio, son las estrategias empleadas para expulsar el acento otro, hacia la defensa de la pureza del idioma patrio. De manera parecida a como años más tarde procedería Lugones en $E l$ payador, identificando anarquía del lenguaje con desórdenes políticos, y marcando de tal manera la homologación entre actitudes sociales y conveniencias lingüísticas, en Los trasplantados la corrupción del español se configura como una peligrosa fuerza irracional 
que provoca la pérdida de la identidad: los hispanoamericanos desprecian la patria, desperdician su riqueza, olvidan su lengua. Este lento despojo conlleva la enfermedad que los exilia de la patria: "somos los seres sin patria" (I 331), admite Juan Gregorio, órganos sin cuerpo condenados irremediablemente a la corrupción biológica y moral.

\section{BIBLIOGRAFÍA}

Ara, Guillermo. La novela naturalista hispanoamericana. Buenos Aires: Eudeba, 1965.

Blest Gana, Alberto. "Literatura chilena: algunas consideraciones sobre ella (1861)". Ed. Norma Clan y Wilfredo H. Corral. Los novelistas como críticos. México: FCE, 1991. 46-58.

Los trasplantados. 2 vols. París: Garnier Hermanos, 1904.

Cánepa, Gina. "Folletines históricos del Chile independiente y su articulación con la novela naturalista”. Hispamérica, XVII, 50 (1988): 23-34.

Dalmaroni, Miguel. Una república de las letras. Lugones, Rojas, Pairó. Escritores argentinos y Estado. Rosario: Beatriz Viterbo, 2006.

Durán Luzio, Juan. "Entre el infierno y el cielo: dos obras de la narrativa chilena en 1904". Revista iberoamericana. LX, 168-169 (1994): 915-924.

Gelpí, Juan G. Literatura y paternalismo en Puerto Rico. San Juan: Editorial de la Universidad de Puerto Rico, 1993.

Hostos, Eugenio María de. Obras completas. Tratado de sociología [1901]. Vol. XVII. La Habana: Cultural, 1939.

Latcham, Ricardo. "Blest Gana y la novela realista" [1958]. Varia lección. Santiago de Chile: Ediciones de la Dirección de Bibliotecas, Archivos y Museos, 2000.

Mariátegui, José Carlos. "El florecimiento de las literaturas nacionales". Comp. Álvaro Fernández Bravo. La invención de la nación. Lecturas de la identidad de Herder a Homi Bhabha. Buenos Aires: Manantial, 2000. 67-73.

Nouzeilles, Gabriela. Ficciones somáticas. Naturalismo, nacionalismo y politicas médicas del cuerpo (Argentina 1880-1910). Rosario: Beatriz Viterbo, 2000.

Ramos, Julio. Desencuentros de la modernidad en América Latina. Literatura y política en el siglo XIX. México: FCE. 1989.

"Faceless Tongues. Language and Citizenship in Nineteenth-Century Latin America". Ed. Angelika Bammer. Displacement. Cultural Identities in Question. Bloomington-Indianapolis: Indiana University Press, 1994. 25-46.

Rodríguez Pérsico, Adriana. "Las fronteras de la identidad. La pregunta por la identidad nacional”. Hispamérica, XXII, 64-65 (1993): 23-48.

Silva Castro, Raúl. Alberto Blest Gana (1830-1920). Estudio biográfico y crítico. Santiago: Universitaria, 1941.

Sommer, Doris. Foudational Ficcions. The National Romances of Latin America. BerkeleyOxford: University of Californa Press, 1991. 
Terán, Oscar. Vida intelectual en el Buenos Aires fin-de-siglo (1880-1910). Derivas de la cultura cientifica. Buenos Aires: FCE, 2000.

PALABRAS ClaVE: naturalismo, enfermedad, identidad nacional, lengua.

KEY WORDS: Naturalism, positivism, illness, national identity, language. 